was distinctly attacked. In nature the magnesian micas are far more easily alterable than muscovite, a fact which is reiterated by these experiments. Again, orthoclase was slightly dissolved, albite nuch more so, and oligoclase gave a reaction between the two; that is, more than the one, less than the other. In other words, the plagioclase feldspars alter more easily than orthoclase, as is apparent in the study of the rocks themselves.

In order to bring out the latter point more clearly, a series of rocks which had been analyzed in the laboratory of the U.S. Geological Survey, was placed in a row of bottles, and treated just as the mineral species had been, with water and phenolphthalein. A granite and an amphibole gabbro gave no alkaline reaction. A rhyolite, trachyte, leucite basalt, feldspar basalt, and diorite gave faint traces of color. Granitite, gneiss, phonolite, diabase, and camptonite yielded distinct alkaline colorations.

In all of these instances the production of color is doubtless due to the solution from the mineral or rock of alkaline silicates. The noteworthy point is the quickness with which the reaction can be obtained. With minerals like cancrinite, sodalite, natrolite, pectolite, and apophyllite, the reaction is striking enough to be used as a lecture-table experiment.

[CONTRIBUTION FROM THE LABORATORIES OF THE MASSACHUSETTS INSTITUTE OF TECHNOLOGY.]

\title{
THE SOLUBILITY OF SALTS OF WEAK ACIDS IN STRONGER ACIDS. ${ }^{1}$
}

\author{
By Arthur A. Noyes and Dayd schwartz. \\ Received August 29, 2898 .
}

I. PURPOSE OF THE INVESTIGATION.

$7 \mathrm{HE}$ theory of the influence of one electrolyte on the solubility of another whose ions differ from those of the first, has up to this time, in spite of the practical importance of the question, been developed and tested only in a very incomplete way. A few years ago, to be sure, the influence on the solubility of a strongly dissociated salt by another of approximately the same dissociation was calculated by one of us, ${ }^{2}$ and was experimentally determined in the case of thallium chloride in

1 Read at the Boston Meeting of the American Chemical Society, August, 1898 .

2 Ztschr. phys. Chem., 6, 262. 
the presence of potassium nitrate and sodium acetate, an approximate agreement being found to exist. A case of greater importance, however, is that in which a weakly dissociated substance is formed by the reaction, such as takes place in the action of a strong acid on the salt of a weaker acid; for in that case the change in solubility is very great. The purpose of this article is to derive theoretically the equations applicable to this case, and to present the results of an experimental investigation of the correctness of these equations. We have accordingly determined the solubility of silver benzoate in nitric acid, a very strong acid, and in chloracetic acid, a comparatively wea $k$ one at different concentrations, and compared the observed with the theoretical values. We will first describe the method of carrying out the experiments and then present the results.

\section{DESCRIPTION OF THE EXPERIMENTS.}

The silver benzoate was prepared by adding to an excess of commercial benzoic acid a solution of sodium carbonate, boiling until the solution was freed from carbon dioxide, and then treating the solution with silver nitrate. The precipitate thus obtained was washed with water and crystallized twice out of boiling water. Its purity was established by ignition and weighing the resulting silver; the amount found agreed with that calculated in two determinations within two-tenths milligram.

The nitric acid solution was prepared from a commercial chemically pure acid which was free from chlorine and which on evaporation left only an inappreciable residue. The chloracetic acid consisted of that portion of a commercial sample which boiled between $I 85^{\circ}$ and $186^{\circ}$. The strengths of these solutions were determined with a sodium hydroxide solution which had been titrated against a sample of succinic acid, the purity of the latter having been proved by a measurement of its electrical conductivity.

The saturation of the solutions was effected by rotation in the previously described apparatus' at a temperature of $25^{\circ}$. In each case the determinations were made in pairs, so that the condition of saturation was approached from a higher as well as

1 Ztschr.phvs. Chem., $9,603$. 
from a lower temperature. After a rotation of at least eight hours, the solutions were filtered, since they would not completely settle; and a portion of $100 \mathrm{cc}$. was at once measured out with a pipette and titrated with a twentieth-normal solution of potassium thiocyanate with the addition of nitric acid and ferric alum as indicator.

3. THE EXPERIMENTAL RESLITS.

The following tables contain the results of all the solubility determinations. The numbers express the millimols of silver benzoate dissolved in one liter. The values which were obtained by cooling the solutions to $25^{\circ}$ are placed under the heading " supersaturated," while those obtained by heating to $25^{\circ}$ are designated as "undersaturated."

SOLubILITY OF SIITER BenzoATE Ix PLRE WATER,

\begin{tabular}{|c|c|c|c|}
\hline $\begin{array}{l}\text { Undersaturated. } \\
\text { II. } 40\end{array}$ & $\begin{array}{c}\text { Supersaturated. } \\
\text { I } 2.04\end{array}$ & $\begin{array}{l}\text { Endersaturated. } \\
\qquad x .6 \mathrm{I}^{\mathrm{I}}\end{array}$ & $\begin{array}{c}\text { Supersaturated. } \\
\text { II. } 68\end{array}$ \\
\hline I I. 43 & I 2.44 & I I. $6 \mathrm{I}^{3}$ & II .62 \\
\hline I I. 43 & 12.74 & I $.63^{\prime}$ & II. 66 \\
\hline Ir. 49 & 12.27 & I 1.46 & I I.97 \\
\hline 11.47 & I 2.14 & $12.14^{2}$ & 12.35 \\
\hline II . 42 & 12.24 & II. 45 & $13.86^{3}$ \\
\hline II 42 & II.96 & II. 40 & I 2.86 \\
\hline$\ldots$ & $\cdots$ & II.43 & 12.92 \\
\hline
\end{tabular}

Mean of the undersaturated solutions: II.47 \pm 0.017 or I I. $44 \pm 0.007$.

Mean of the supersaturated solutions : $\mathrm{I} 2.2 \mathrm{I} \pm 0.09 \mathrm{I}$.

Solubitity of Silver Benzoate in Nitric Acid.

Concentration of acid. Concentration of acid. 4.435 millimols per liter. $8.8 \%$ millimols per liter. Under- Supersaturated. saturated.

13.97

13.92

I 3.95

I 3.94

$14.2 \mathrm{I}^{1}$

I3.95

13.95 $\pm 0.006$ 14.75 I 5.07 14.87 I 4.86 I4. $16^{1}$ 14.62

Undersuturated superI 7.00 16.96 saturated

I $7 \cdot 34$

I 8.20

17.19

I7. I I 16.75 17.64

....

$$
\frac{\cdots}{16.98}
$$$$
14.83
$$

$$
\pm 0.054
$$

Concentration of acid. 8.915 millimols per liter. Under- Supersaturated. saturated.

I $7.15 \quad 17.57$

I7.15 18.07

$\ldots \ldots$

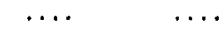

$\ldots \ldots$

$\ldots, \quad \ldots, \quad \ldots$

$17.57 \quad 17.15 \quad 17.82$ 士0.174 $\pm 0.000 \quad \pm 0.179$

1 Onitted in the calculation of the second mean.

2 Omitted in the calculation of both means.

8 Oritted in the calculation of the mean 


\begin{tabular}{|c|c|c|c|c|c|}
\hline \multicolumn{2}{|c|}{$\begin{array}{l}\text { Concentration of acid. } \\
\text { 17.74 millimols per liter. }\end{array}$} & \multicolumn{2}{|c|}{$\begin{array}{l}\text { Concentration of acid. } \\
\text { I7.83 millimols per liter. }\end{array}$} & \multicolumn{2}{|c|}{$\begin{array}{l}\text { Concentration of acid. } \\
26.74 \text { millimols per liter. }\end{array}$} \\
\hline $\begin{array}{l}\text { Under- } \\
\text { saturated. }\end{array}$ & $\begin{array}{l}\text { Super. } \\
\text { saturated. }\end{array}$ & $\begin{array}{l}\text { Under- } \\
\text { saturated. }\end{array}$ & $\begin{array}{l}\text { Super- } \\
\text { saturated. }\end{array}$ & $\begin{array}{l}\text { Under- } \\
\text { saturated. }\end{array}$ & $\begin{array}{l}\text { Super- } \\
\text { saturated. }\end{array}$ \\
\hline 23.27 & 24.07 & 23.47 & 24.83 & 30.70 & 31.10 \\
\hline 23.23 & 24.21 & 23.55 & 24.97 & 30.68 & 35.12 \\
\hline $23.46^{1}$ & 23.93 & $\ldots$ & ... & 30.77 & 31.93 \\
\hline 23.21 & 23.97 & $\cdots$ & $\cdots$ & 30.67 & 33.30 \\
\hline & & & 24.90 & & 32.86 \\
\hline \pm 0 & \pm 0.048 & \pm 0.029 & \pm 0.050 & \pm 0.016 & \pm 0.674 \\
\hline
\end{tabular}

SOLUBILITY OF SILVER BENZOATE IN CHLORACETIC ACID.

\begin{tabular}{|c|c|c|c|c|c|}
\hline Concentrati & 1 of acid. & $\begin{array}{l}\text { Concentro } \\
7.87 \mathrm{millim}\end{array}$ & on of acid. & Concentr & $\begin{array}{l}\text { ion of acid. } \\
\text { is per liter. }\end{array}$ \\
\hline $\begin{array}{l}5 \text { millim } \\
\text { Under- }\end{array}$ & & & & $15.74 \mathrm{mint1}$ & \\
\hline saturated. & saturated. & $\begin{array}{l}\text { Under- } \\
\text { saturated. }\end{array}$ & $\begin{array}{l}\text { Super- } \\
\text { saturated. }\end{array}$ & $\begin{array}{l}\text { Under- } \\
\text { saturated. }\end{array}$ & $\begin{array}{l}\text { 5uper- } \\
\text { saturated }\end{array}$ \\
\hline I 3.86 & I3.86 & 16.10 & 16.18 & 20.92 & $2 \mathrm{I} . \mathrm{I}_{3}$ \\
\hline $13.8 \mathrm{I}$ & 14.29 & I6. 10 & I6.36 & 20.94 & $25.09^{1}$ \\
\hline I3.86 & I4.I6 & I6. I 2 & I6. 56 & 20.90 & 21.40 \\
\hline I3.86 & 14.16 & I6. I4 & 16.38 & 20.95 & 21.09 \\
\hline I 3.85 & 4.12 & 16.12 & 37 & 0.93 & $.2 \mathrm{I}$ \\
\hline & \pm 0 & \pm 0.008 & \pm 0.050 & \pm 0.010 & \pm 0.076 \\
\hline
\end{tabular}

The relatively large number of solubility determinations in pure water were carried out because the supersaturated and the undersaturated solutions did not correspond. The seven pairs of values in the first two columns were obtained after six hours' rotation of the solutions; the first five in the third and fourth columns, after twenty-four hours; and the last three in these columns, after seventy-two hours. The saturation seems, however, to depend much more on the quantity and physical condition of the solid substance than on the time. As is seen, the mean of the supersaturated solutions is six and four-tenths per cent. higher than that of the undersaturated. From the fact, however, that the separate undersaturated values agree well with one another, while the supersaturated ones show large variations, the former may be considered as essentially correct. In the two cases, the average deviations of the means amount to 0.15 and 0.75 per cent. respectively, and if these values were combined according to the laws of probability, then a relative weight of only four per cent. would have to be ascribed to the supersaturated. Paul ${ }^{2}$ had exactly the same experience in his researches on the solubility of certain organic acids whose phys-

1 Omitted in the calculation of the mean.

2 Ztschr.phys. Chem., I4, II2. 
ical condition is similar to that of silver benzoate. He also came to the conclusion that the undersaturated values are the reliable ones. The same difference between the results of the two methods of determination also exists in the presence of the two acids. We have therefore taken the mean value of the undersaturated solutions as the more reliable. These will be brought together in a table below.

\section{THE THEORY OF SOLUBILITY EFFECT.}

We will now determine whether the experimental values are in accordance with the requirements of the theory of solubility effect. In order to do this, it is necessary to derive from the laws of mass-action the equations which should express the relation between the solubility of the silver benzoate in pure water and its solubility in the solutions of nitric acid and of chloracetic acid. This we will now proceed to do in a general form.

The problem is the determination of the solubility of a di-ionic electrolyte $A B$ in a solution which contains a known amount of a second di-ionic electrolyte CD. (An influence on the solubility takes place, since by metathesis certain amounts of the substances $A D$ and $C B$ are produced.) The solubility of the body $A B$ in pure water and the dissociation relations of all the substances involved are to be assumed to be known.

First it is to be noticed that the following eight substances are present in the solution: the four undissociated substances $A B$, $C D, A D$, and $C B$; and the four ions, $A, B, C$, and $D$. We will designate the concentrations of the ions by these same large letters, and those of the undissociated molecules $A B, C D, A D$, and $\mathrm{CB}$ by the small letters $a, b, c$, and $d$ respectively. If now the solution contains the known amount $n$ of the substance $C D$ in one liter, and the solubility in it of the substance $A B$ is $m$, evidently the following equations hold true:

$$
\begin{aligned}
& a+c+\mathrm{A}=m, \\
& a+d+\mathrm{B}=m, \\
& b+c+\mathrm{D}=n, \\
& b+d+\mathrm{C}=n .
\end{aligned}
$$

Further if $m_{0}$ is the solubility of $\mathrm{AB}$ in pure water, and $a_{0}$ is 
the corresponding dissociation, we obtain as the expression of the solubility principles: ${ }^{1}$

$$
\begin{gathered}
a=m_{0}\left(\mathrm{I}-a_{0}\right) . \\
\mathrm{A} \times \mathrm{B}=m_{0}^{2} a_{0}^{2}=k_{a},
\end{gathered}
$$

where $k_{a}$ is used for brevity to express the product $m_{0}{ }^{2} a_{0}{ }^{2}$. Finally the following three dissociation equations apply :

$$
\begin{aligned}
& \frac{\mathrm{C} \times \mathrm{D}}{b}=k_{b}, \\
& \frac{\mathrm{A} \times \mathrm{D}}{c}=k_{c}, \\
& \frac{\mathrm{C} \times \mathrm{B}}{d}=k_{d},
\end{aligned}
$$

and

where $k_{b}, k_{c}$, and $k_{d}$ are the dissociation constants of the substances $C D, A D$, and $C B$ respectively.

We now have nine equations and nine unknown quantities; namely, the concentrations of the eight different kinds of molecules and the value $m$. Theoretically then this latter quantity can be determined and we have convinced ourselves that the necessary eliminations can be carried out; that is to say, an equation can be obtained which contains as an unknown quantity only the quantity $m$, but the equation is of a high degree in $m$ and consists of a very large number (probably a hundred or more) of terms. Accordingly the calculation has not been carried out, especially since this most general case finds no practical application, because at least one of the substances $C D, A D$, and $C B$ must be a salt to which the theoretical laws of dissociation do not apply.

There is a possibility of simplifying the problem since a sufficiently accurate knowledge of one or two of the three values $b$, $c$, and $d$ can be obtained from other sources, whereby the corresponding dissociation equations can be dispensed with in the elimination, and the algebraic solution becomes much simpler. For, the dissociation of a substance in pure water can always be determined by means of conductivity measurements, and in the case of a largely dissociated substance, like a salt, or a strong acid or base in dilute solution, its disso-

1 Ztschr. phys. Chem., 4. 372; 9,603. 
ciation is influenced so little by the presence of other substances that its undissociated amount can be quite accurately estimated by a short approximation process. Since now at least one of the three bodies $C D, A D$, and $C B$ must be a salt, it is always possible to simplify in this manner.

The simplest cases are those in which all three of the substances $C D, A D$, and $C B$, or the last two of these, are strongly dissociated substances, so that the quantities $b, c$, and $d$, or the last two of them, can be determined from the conductivities of the salts in pure water. The solubility of thallium chloride in potassium nitrate, referred to at the beginning of this article, is one example of this kind. That of silver benzoate in sodium nitrate would be another. This case, is not, however, of present interest, as we have no new experiments of the kind to communicate. ${ }^{1}$

The next simplest case is that where $C D$ and $A D$ (or $C B$ ) are strongly dissociating substances, while $\mathrm{CB}$ (or $\mathrm{AD}$ ) is only slightly or moderately dissociated. In this case the quantities $b$ and $c$ (or $d$ ) can be determined from conductivity measurements, and can therefore be regarded as known quantities in the derivation of the fnal equation, so that equations (7) and (8) (or (9)), which contain them, can be dispensed with. The solubility of the silver benzoate in nitric acid is a case of this kind; for nitric acid and silver nitrate are strongly dissociated, and benzoic acid is weakly dissociated.

In order, now, to derive this equation, we assume $b$ and $c$ to be known, so as to have a definite case under consideration, and proceed as follows: For brevity we put

and

$$
\begin{aligned}
& m-a=x, \\
& n-b=l,
\end{aligned}
$$

$l$ being a known quantity, and $x$ the quantity to be determined. By elimination between equations ( 1$),(2)$, and (6), we obtain:

$$
d=\frac{x^{2}-c x-k_{a}}{x-c}
$$

Furthermore we obtain by combining equations (2), (4) and (9): $\quad d=\frac{1}{2}\left(x+l+k_{d} \pm \sqrt{x^{2}+l^{2}+k_{d}^{2}+2 x k_{d}+2 l k_{d}-2 l x}\right)$. 1 For a full discussion of the theory in this case see Noyes: Ztschr, phys. Chem., 27. 
If now we place these two values of $d$ equal to each other and simplify, we obtain the following expression :

$$
\begin{gathered}
x^{3}+(r-2 c) x^{2}+\left(c^{2}-r c-r n+r b-k_{a}\right) x+(r c n-r c b+ \\
\left.k_{a} c-k_{a} r\right)=0,
\end{gathered}
$$

in which $r=\frac{k_{a}}{k_{d}}$. By means of this equation we can calculate the value of $x$, since all the other values are known, and from this we obtain the solubility $m$ by equation (IO). In the case where the substance $A B$ is difficultly soluble and the value $n$ is not very great, the quantities $b$ and $c$ are negligible. Then the following equation applies :

$$
x^{3}+r x^{2}-\left(r n+k_{a}\right) x-k_{a} r=0 .
$$

If further $x$ is very small relatively to $r$, the cubic term may be neglected. In this case :

$$
x^{2}-\left(n+k_{d}\right) x-k_{a}=0 .
$$

The remaining case to be considered is that where only the substance $A D$ (or $C B$ ) is strongly dissociated, both $C D$ and $C B$ (or $\mathrm{AD}$ ) being only slightly or moderately dissociated, so that they follow the theoretical dissociation-law. In this case only the quantity $c$ (or $d$ ) can be regarded as known, and only equation (8) (or (9)) can be dispensed with in the derivation of the solubility equation. For the sake of definiteness we assume $c$ to be known.

The solubility of silver benzoate in chloracetic acid is an example of this case, for chloracetic acid and the benzoic acid produced by the metathesis are weakly dissociated, and the silver chloracetate is much dissociated.

To derive the solubility equation, equations (3), (4), and (7) are solved for $b$ with elimination of $C$ and D, whereby we obtain :

$$
\begin{aligned}
2 b=-(c+d- & \left.2 n-k_{b}\right) \pm \\
& \sqrt{\left(c+d-2 n-k_{b}\right)^{2}+4\left(c n+d n-n^{2}-c d\right)} .
\end{aligned}
$$

Eliminating $B$ and $C$ from equations (2), (4), and (9), we obtain :

$$
2 b=\frac{2(n-d)(x-d)-2 k_{d} d}{(x-d)} .
$$


If now we place these values of $2 b$ equal to each other, simplify, and substitute in the resulting equation the value of $d$ derived from equations (I), (2), and (6), viz., $d=\frac{x^{2}-c x-k_{r}}{x-c}$, after simplification we obtain :

$$
r x^{5}+(\mathrm{I}-3 c r) x^{4}+\left(3 c^{2} r-3 c+k_{b}-2 k_{d}\right) x^{3}+\left(4 c k_{d}-c^{3} r+\right.
$$
$\left.3 c^{2}-2 k_{i z}-2 c k_{\dot{b}}+s\right) x^{2}+\left(k_{a} k_{a}-2 c^{2} k_{a}+3 c k_{a}-c^{3}-k_{a} k_{b}+c^{2} k_{\dot{b}}-\right.$ $n s-c s) x+\left(k_{a}{ }^{2}-c k_{a} k_{a}-c k_{a}+c k_{a} k_{b}+c n s-k_{a} s\right)=0$, in which $x=m-a ; r=\frac{k_{a}}{k_{a}}$; and $s=\frac{k_{a} k_{b}}{k_{a}}$. In very dilute solutions, or in general as an approximation, $c$ may be placed equal to 0 , when follows :

$$
\begin{array}{r}
r x^{5}+x^{4}+\left(k_{b}-2 k_{d}\right) x^{3}+\left(s-2 k_{a}\right) x^{2}+\left(k_{a} k_{a}-k_{a} k_{b}-n s\right) x+ \\
\left(k_{a}{ }^{2}-k_{a} s\right)=0 .
\end{array}
$$

In certain cases, for example, when $k_{b}$ is negligible in comparison with $k_{d}$, or the reverse, a further simplification may easily be made.

\section{COMPARISON OF THE EXPERIMENTAL AND THEORETICAL, VALUES.}

We have, now, by means of equation (12), calculated the theoretical solubility of silver benzoate in the various solutions of nitric acid, making use of the following data: $k_{a}=m_{0}{ }^{2} a_{0}{ }^{2}=$ $0.000093^{2}$ (since the solubility in pure water, $m_{0}=0.01144$, and the corresponding dissociation-value, $a_{0}=0.844$, according to conductivity measurements of our own) ; the dissociation constant of benzoic acid, $k_{d}=0.000060$, according to Ostwald's measurements, whence the ratio $r=I .553$. The values of $c$ in the different cases were deduced from the conductivity of silver nitrate as determined by Kohlrausch. The equations were solved in this case and also in that of the chloracetic acid, by repeated substitution of estimated values of $x$ until the exact root was found.'

The solubility of silver benzoate in chloracetic acid has been calculated by equation (15), using the same values of $k_{\alpha}$ and $k_{\alpha}$, as before, putting the dissociation constant of chloracetic acid,

1 For further details of the method of calculation, reference is made to a more extended article on the theory in the current volume of the Zeitschrift für physikalische Chemie. 
$k^{b}=0.00155$, in accordance with the measurements of Ostwald, and determining $c$ from conductivity measurements.

In the following tables are given the experimental and the theoretical values, together with the percentage differences between them.

SOLUBIIITY OF THE Silver BenzoATE IN NITRIC ACID.

\begin{tabular}{|c|c|c|c|c|}
\hline $\begin{array}{l}\text { Experi- } \\
\text { ment No. }\end{array}$ & $\begin{array}{l}\text { Concentration of } \\
\text { the nitric acid. }\end{array}$ & $\begin{array}{l}\text { Found } \\
\text { solubility. }\end{array}$ & $\begin{array}{l}\text { Calculated } \\
\text { solubility. }\end{array}$ & $\begin{array}{l}\text { Percentage } \\
\text { difference. }\end{array}$ \\
\hline I & 0.00 & o.orI44 & $\ldots \ldots$ & ..... \\
\hline II & 0.004435 & 0.01395 & 0.01406 & +0.78 \\
\hline III & 0.008870 & 0.01698 & 0.01703 & +0.29 \\
\hline IV & 0.008915 & 0.017 I5 & 0.01706 & -0.53 \\
\hline V & 0.01774 & 0.02324 & 0.02390 & +2.76 \\
\hline VI & 0.01783 & 0.02351 & 0.02396 & +1.89 \\
\hline VII & 0.02674 & $0.0307 \mathrm{I}$ & 0.03159 & +2.79 \\
\hline
\end{tabular}

Sol,dbitity of The Sil, ver Benzoate in Chloracetic Acid.

\begin{tabular}{|c|c|c|c|c|}
\hline $\begin{array}{l}\text { Experi- } \\
\text { mett No. }\end{array}$ & $\begin{array}{l}\text { entration of the } \\
\text { loracetic acid. }\end{array}$ & $\begin{array}{l}\text { Found } \\
\text { solubility. }\end{array}$ & $\begin{array}{l}\text { Calculated } \\
\text { solubility. }\end{array}$ & $\begin{array}{l}\text { Percentage } \\
\text { difference. }\end{array}$ \\
\hline I & 0.00 & 0.01 I 44 & $\ldots$. & $\ldots .$. \\
\hline II & 0.003935 & 0.01385 & 0.01368 & -1.24 \\
\hline III & 0.00785 & 0.01612 & 0.01588 & $-\mathrm{I} .5 \mathrm{I}$ \\
\hline IV & 0.01574 & 0.02093 & $0.021 \mathrm{I} 7$ & +I.I3 \\
\hline
\end{tabular}

The agreement between the found and the calculated values is very satisfactory, especially considering the large number of dissociation values used in the calculation; consequently the solubility principles and the validity of the theoretical laws of dissociation in the case of weakly dissociated acids are again confirmed. It is specifically shown by this investigation that the solubility of silver benzoate is increased both hy nitric acid and chloracetic acid in such a way that the product of the concentrations of the $\mathrm{Ag}$ and the $\mathrm{C}_{6} \mathrm{H}_{6} \mathrm{CO}_{2}$ ions remains constant.

[Contributions from the Chemical, Laboratories of the MassachUSETTS INSTITUTE OF TECHNOLOGY.]

\section{THE SOLUBILITY OF ACIDS IN SOLUTIONS OF THE SALTS OF OTHER ACIDS.'}

By Arthur A. Noyes and Edward S. Chapin. Received August 29, I898.

I. PURPOSE OF THE INVESTIGATION.

I $\mathrm{N}$ an article published elsewhere by one of us, ${ }^{2}$ the theory of the influence of one di-ionic electrolyte on the solubility of

1 Read at the Boston meeting of the American Chemical Society, August, 1898 .

2 Ztschr.phys. Chem, 27. 